\title{
Perencanaan Reklamasi Serta Detail Breakwater pada Tersus Galangan Kapal Paciran, Kabupaten Lamongan
}

\author{
Fiany Dara Novelita, Dyah Iriani Widyastuti, dan Cahya Buana \\ Departemen Teknik Sipil, Institut Teknologi Sepuluh Nopember (ITS) \\ e-mail:dyah1961@gmail.com
}

\begin{abstract}
Abstrak - Pertumbuhan kapal di Indonesia tergolong cukup pesat. Pada tahun 2012, menurut data Ikatan Perusahaan Industri Kapal dan Lepas Pantai Indonesia (Iperindo) kebutuhan reparasi dan perawatan kapal di Indonesia mencapai 7,5 - 8 juta gross ton kapal per bulan. Sedangkan jumlah dok dan galangan kapal di Indonesia mencapai sekitar 30 unit saja dengan kapasitas 7 juta GT/tahun. Oleh karenanya dirasa perlu direncanakan galangan kapal baru. Rencana galangan kapal baru berada di Desa Tunggul Kecamatan Paciran, Kabupaten Lamongan. Pantai Utara Jawa di wilayah Propinsi Jawa Timur. Mengacu pada masterplan, dalam tugas akhir ini akan merencanakan reklamasi dan struktur breakwater untuk galangan kapal tersebut. Dalam perencanaan tersus galangan kapal ini diharapkan mampu melayani kapal dengan berat maksimum 10000 DWT. Reklamasi direncakan menggunakan material sirtu pilihan yang pelaksanaannya dilakukan dari daratan menuju laut. Timbunan reklamasi dilakukan pada kedalaman maksimal $-4 \mathrm{mLWS}$ hingga mencapai elevasi +4 mLWS dengan luasan 20.08 Ha. Untuk breakwater ini direncanakan menggunakan tipe rubble mound dengan armour layer berupa batu limestone yang datangkan dari darat yang kemudian dituang ke arah laut. Breakwater ini di-bangun dari elevasi $+4.5 \mathrm{mLWS}$ hingga kedalaman -8 mLWS. Biaya total yang dibutuhkan untuk membangun reklamasi dan breakwater ini adalah sebesar Rp. $578,489,189,000.00$.
\end{abstract}

Kata Kunci-Tersus, Galangan Kapal, Reklamasi, Rubble Mound, Paciran.

\section{PENDAHULUAN}

$P^{\prime}$ ERTUMBUHAN kapal di Indonesia tergolong cukup pesat. Menurut Kementerian Perhubungan mencatat jumlah kapal komersial nasional per Februari 2014 mencapai 13.326 unit atau meningkat $120 \%$ dari Mei 2005. Pada tahun 2012, menurut data Ikatan Perusahaan Industri Kapal dan Lepas Pantai Indonesia (Iperindo) kebutuhan reparasi dan perawatan kapal di Indonesia mencapai 7,5 - 8 juta gross ton kapal per bulan. Sedangkan jumlah dok dan galangan kapal di Indonesia miliki kapasitas 7 juta GT/tahun. Oleh karenanya galangan kapal untuk pembuatan kapal baru juga masih dibutuhkan dan ditingkatkan jumlahnya.

Dirasa perlu direncanakan galangan kapal baru. Rencana galangan kapal baru berada di Desa Tunggul Kecamatan Paciran, Kabupaten Lamongan. Pantai Utara Jawa di wilayah Propinsi Jawa Timur. Hal ini disebabkan besarnya volume lalu lintas kapal di laut Jawa dan akan memudahkan bagi kapal untuk merapat dan nantinya melaut kembali. Lahan yang digunakan untuk galangan tersebut adalah lahan reklamasi. Letak galangan kapal tersebut berada pada pantai utara jawa, sehingga dirasa perlu untuk merencanakan breakwater. Hal ini dimaksudkan agar kapal yang memasuki

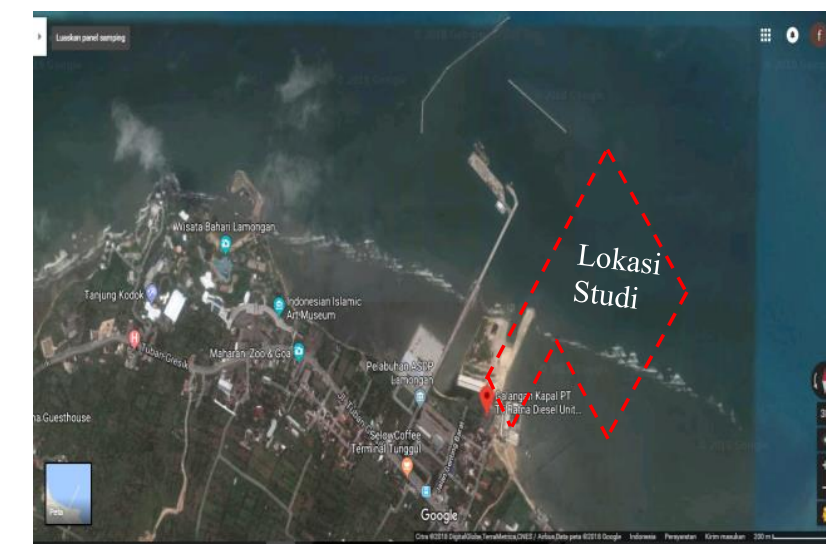

Gambar 1. Lokasi Tersus Galangan Kapal Paciran, Lamongan

galanagn kapal tersebut aman dari gelombang [1]. Mengacu pada masterplan, penulis akan merencanakan reklamasi dan struktur breakwater untuk galangan kapal tersebut. Diharapkan mampu memenuhi kebutuhan akan fasilitas perawatan, perbaikan dan dok untuk pembuatan kapal-kapal baru.

Dalam tugas akhir ini kami akan membahas permasalahan sebagai berikut:

1. Lahan yang digunakan untuk galangan kapal baru di Paciran menggunakan lahan reklamasi. Sehingga perlu pe-rencanaan reklamasi seluas $\pm 20 \mathrm{Ha}$, termasuk talud.

2. Dibutuhkan perairan yang tenang sepanjang tahun untuk keamanan dan kestabilan kapal yang akan masuk ke dalam galangan. Diperlukan perencanaan breakwater untuk melindungi perairan dari pengaruh gelombang dari laut dalam.

3. Reklamasi akan dilakasanakan hingga kedalaman $-4 \mathrm{~m}$ LWS, sehingga perlu adanya perencanaan yang efisien dalam metode pelaksanaan serta perlu adanya perhitungan anggaran biaya dalam perencanaannya. Selain itu perlu adanya perencanaan breakwater yang efisien dalam meto-de pelaksanaan serta perlu adanya perhitungan anggaran biaya dalam perencanaannya

Tujuan yang akan dicapai dari pembahsana tugas akhir ini adalah :

1. Mampu merencanakan timbunan reklamasi seluas \pm 20 $\mathrm{Ha}$.

2. Mampu merencanakan detail breakwater yang mampu melindungi dari pengaruh gelombang dar laut dalam.

3. Mampu merencanakan metode pelaksanaan untuk reklamasi dan detail breakwater, serta merencanakan anggaran biaya.

Lingkup pekerjaan dalam pengerjaan tugas akhir ini adalah:

1. Evaluasi layout perairan 


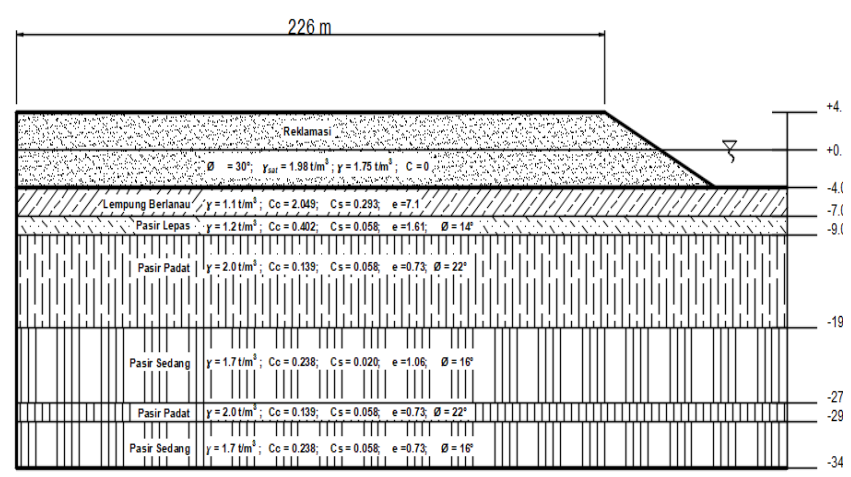

Gambar 2. Sketsa Perencanaan Reklamasi

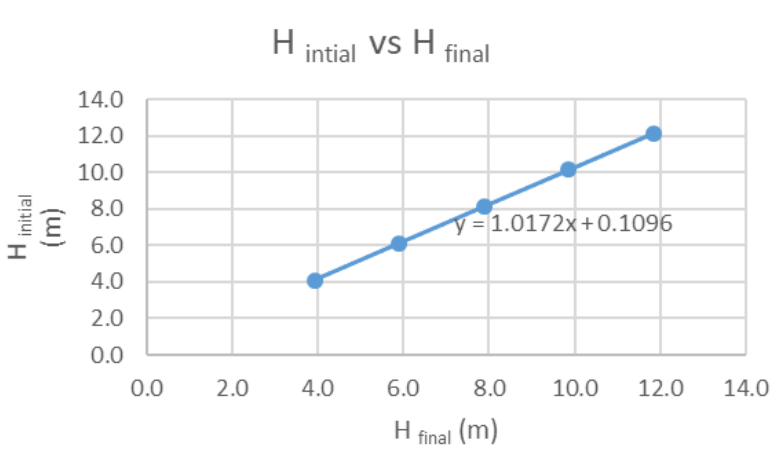

Gambar 3. Grafik Hubungan $\mathrm{H}$ insial vs $\mathrm{H}$ final

2. Perencanaan reklamasi dan perbaikan tanah bila diperlukan

3. Perencanaan detail breakwater

4. Metode pelaksanaan reklamasi dan breakwater

5. Analisa anggaran biaya

Batasan masalah dalam pengerjaan ini adalah :

1. Data yang digunakan adalah data skunder

2. Lokasi quarry sudah ditentukan

3. Tidak membahas masalah sedimentasi.

4. Tidak membahas saran bantu navigasi pealayaran (SBNP).

5. Pembahasan hanya dikhususkan pada perencanaan layout perairan, perncanaan reklamasi, dan perencanaan breakwater.

Lokasi perencanaan tersus galangan kapal direncanakan berada di pantai utara Jawa desa Tunggul, Kecamatan Paciran, Kabupaten Lamongan, untuk bagian barat berbatasan langsung dengan dermaga ASDPyang dapat dilihat pada Gambar 1.

\section{METODOLOGI}

Metodologi penelitian dapat dilihat pada Gambar 4.

\section{PEMBAHASAN}

\section{A. Perencanaan Reklamasi}

Elevasi rencana timbunan berada pada +4 mLWS Kedalaman seabed maksimum adalah -4 mLWS, maka tinggi akhir timbunan yang direncanakan adalah 8 meter. Sketsa timbunan reklamasi dapat dilihat pada Gambar 2.

Sesuai dengan perencanaan, tinggi timbunan akhir $\left(\mathrm{H}_{\text {final }}\right)$ yang dibutuhkan adalah sebesar $8 \mathrm{~m}$, maka tinggi timbunan

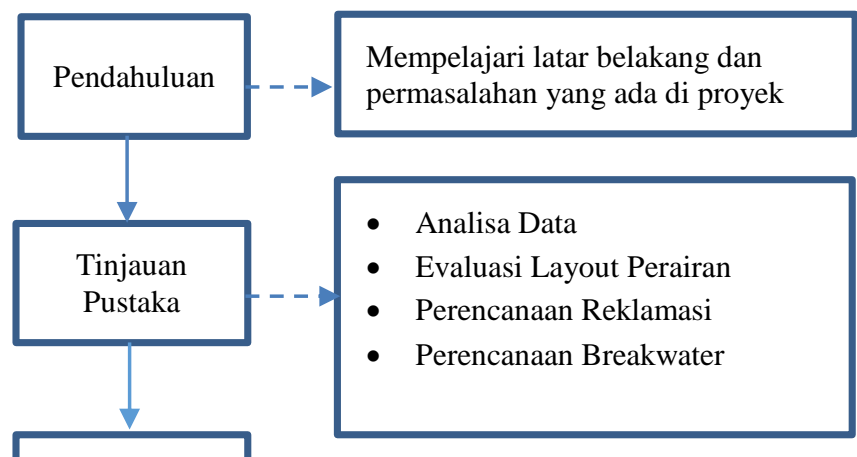

A
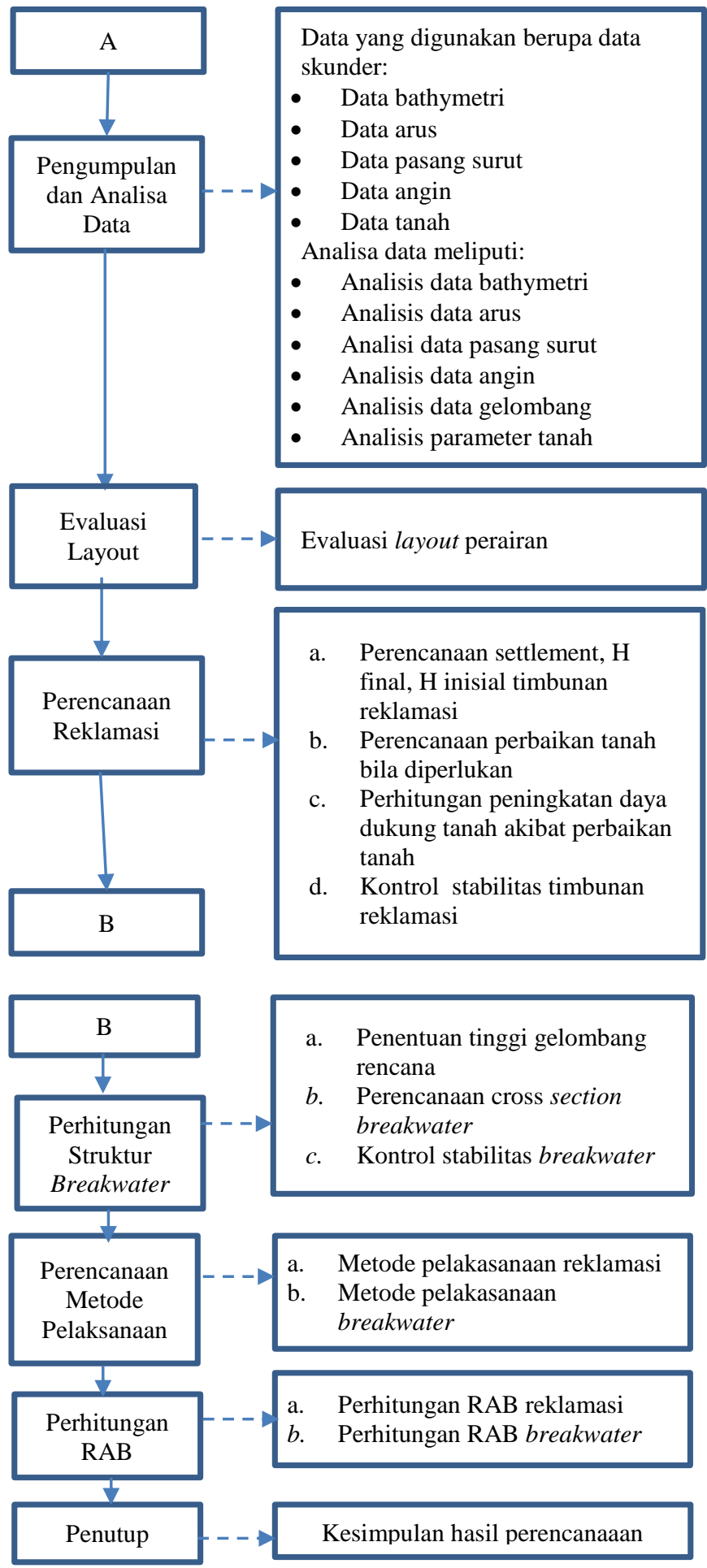

Gambar 4. Metodologi Penelitian 


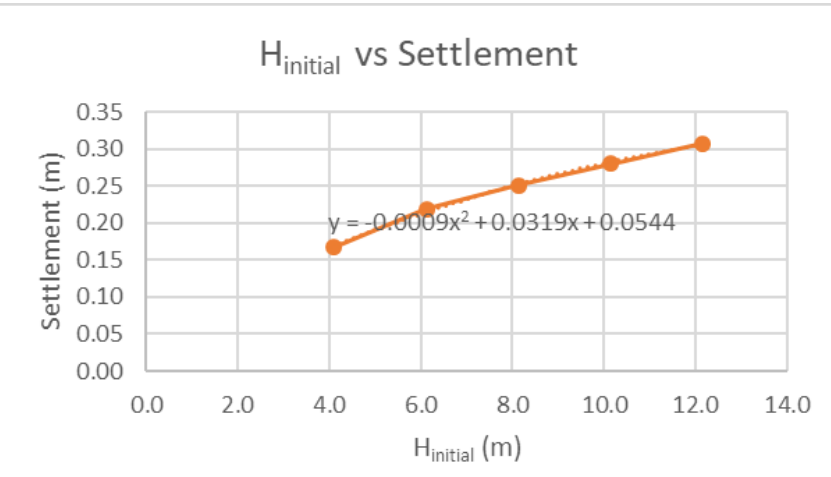

Gambar 5. Grafik Hubungan Antara Tinggi Timbunan Awal dengan Penurunan

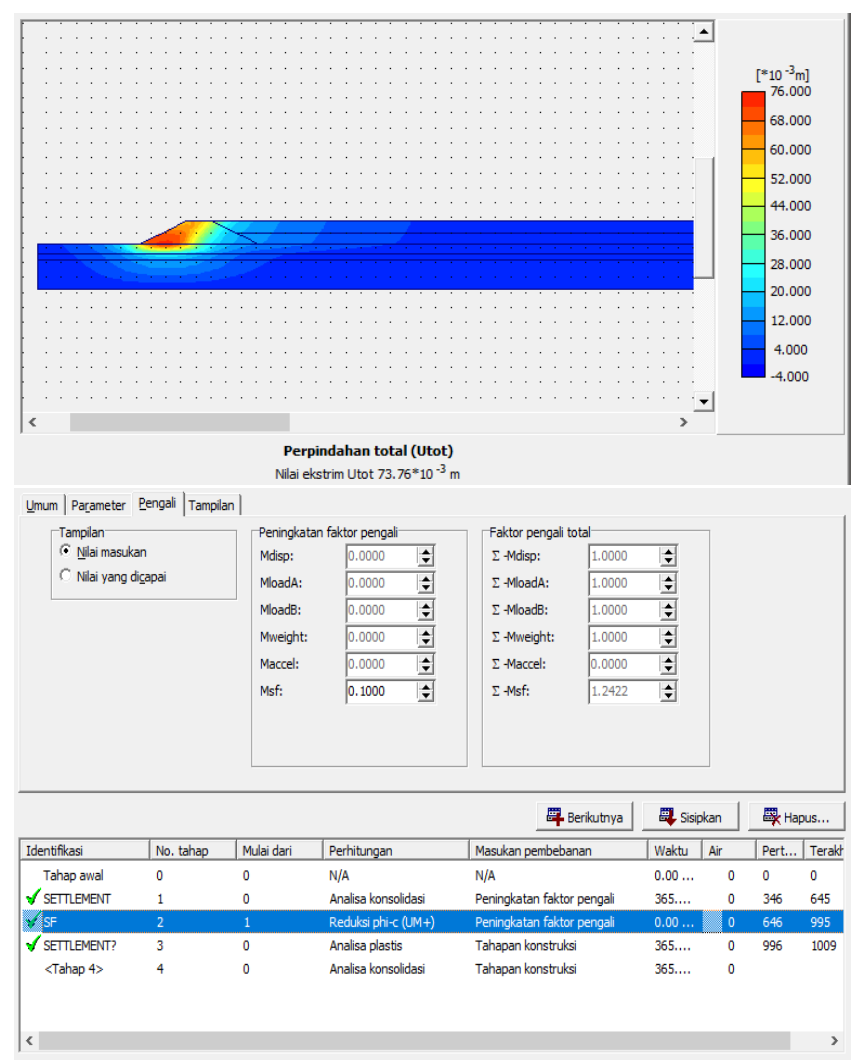

Gambar 6. Hasil Analisa Menggunakan Software Plaxis

awal dapat dicari menggunakan persamaan garis lurus yang dihasilkan dari Gambar 3.

$$
\begin{aligned}
H_{\text {initial }} & =1.02 H_{\text {final }}+0.11 \\
& =1.02 \times 8 \mathrm{~m}-0.11 \\
& =8.26 \mathrm{~m} \approx 8.3 \mathrm{~m}
\end{aligned}
$$

Untuk mencari penurunan yang terjadi menggunakan grafik hubungan antara tinggi timbunan awal dengan penurunan seperti pada Gambar 5.

$$
\begin{aligned}
S_{\text {tot }} & =-0.001 x^{2}+0.0319 x+0.054 \\
& =-0.001(8.4)^{2}+0.0319(8.4)+0.054 \\
& =0.25 \mathrm{~m} \approx 0.3 \mathrm{~m}
\end{aligned}
$$

Waktu yang dibutuhkan untuk pemampatan dengan derajat konsolidasi sebesar $80 \%$ adalah sebagai berikut.

$$
\begin{gathered}
t=\frac{0.567(1.5 \mathrm{~m})^{2}}{0.0363 \mathrm{~m}^{2} / \mathrm{ming} \mathrm{mu}} \\
=35 \mathrm{ming} \mathrm{u}
\end{gathered}
$$

Karena waktu yang dibutuhkan untuk pemampatan relatif cepat, maka tidak diperlukan penggunaan PVD

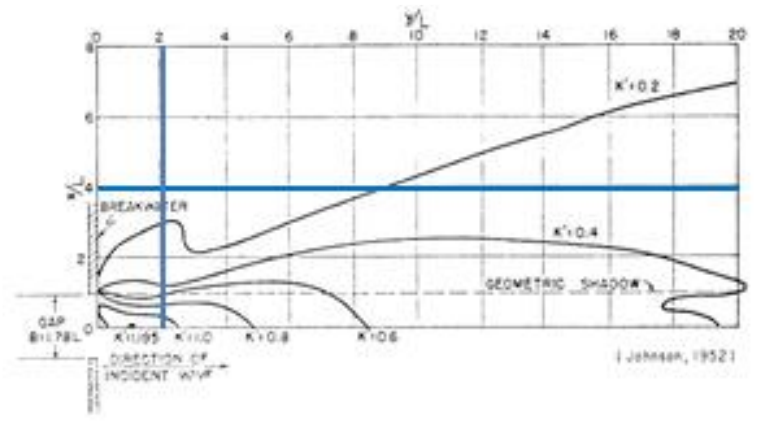

Gambar 7. Diagram Difraksi dengan B/L=1.78

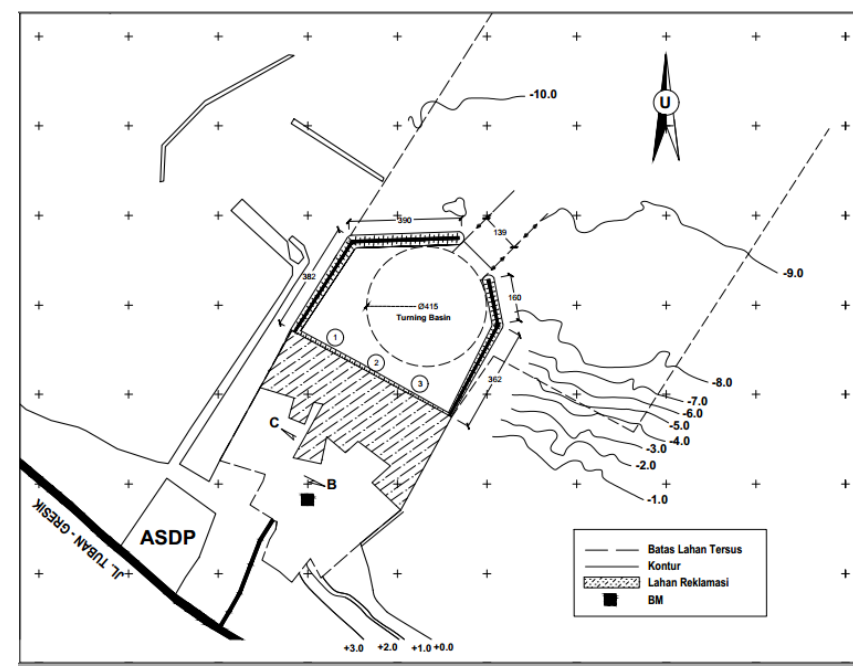

Gambar 8. Layout Breakwater Baru

Tabel 1.

Tinggi Gelombang Setelah Difraksi pada Titik yang Ditinjau

\begin{tabular}{cccccccccc}
\hline \hline Titik & $\begin{array}{c}\mathrm{H}_{50} \\
(\mathrm{~m})\end{array}$ & $\begin{array}{c}\mathrm{T} \\
(\mathrm{s})\end{array}$ & $\begin{array}{c}\mathrm{L} \\
(\mathrm{m})\end{array}$ & $\begin{array}{c}\mathrm{x} \\
(\mathrm{m})\end{array}$ & $\begin{array}{c}\mathrm{y} \\
(\mathrm{m})\end{array}$ & $\mathrm{x} / \mathrm{L}$ & $\mathrm{y} / \mathrm{L}$ & $\mathrm{K}$ & $\begin{array}{c}\mathrm{H} \\
(\mathrm{m})\end{array}$ \\
\hline 1 & 3.7 & 10 & 89 & 333 & 162 & 3.7 & 1.8 & 0.2 & 0.7 \\
2 & 3.7 & 10 & 89 & 218 & 277 & 2.5 & 3.1 & 0.2 & 0.7 \\
3 & 3.7 & 10 & 89 & 66 & 349 & 0.7 & 3.9 & 0.2 & 0.7 \\
\hline \hline
\end{tabular}

Nilai safety factor (SF) terhadap puncture failure dapat dihitung sebagai berikut

$$
S F=\frac{12.5 \mathrm{KPa} 99}{1.1 \mathrm{t} / \mathrm{m}^{3} \times 8.4 \mathrm{~m}}=12.7 \text { (aman) }
$$

Dalam pengecekan stabilitas sliding rotasional menggunakan media bantu plaxis. Dalam memodelkannya didapatkan $\mathrm{SF}=1.242$ yang berarti aman terhadap sliding rotasional. Hasil analisa menggunakan software plaxis dapat dilihat pada Gambar 6.

\section{B. Perencanaan Breakwater}

Berdasarkan masterplan, breakwater ini akan dibangun diperairan dangkal dengan kedalaman maksimum adalah -8 mLWS. Tinggi gelombang pada laut dalam $\left(\mathrm{H}_{\mathrm{o}}\right)$ akan terdifraksi. Dari masterplan pengembangan Tersus untuk mendapatkan koefisien difraksi menggunakan grafik koefisien difraksi dengan $\mathrm{B} / \mathrm{L}=1.78$ dapat dilihat pada Gambar 7.

Sehingga tinggi gelombang setelah difraksi pada titik titik yang ditinjau dapat dilihat pada Tabel 1.

Akan tetapi letak kepala breakwater terletak pada area turning basin, maka diperlukan perencanaan layout breakwater baru yang dapat dilihat pada Gambar 8 .

Sehingga untuk mendapatkan koefisien difraksi menggunakan grafik koefisien difraksi dengan $\mathrm{B} / \mathrm{L}=1.64$ yang 


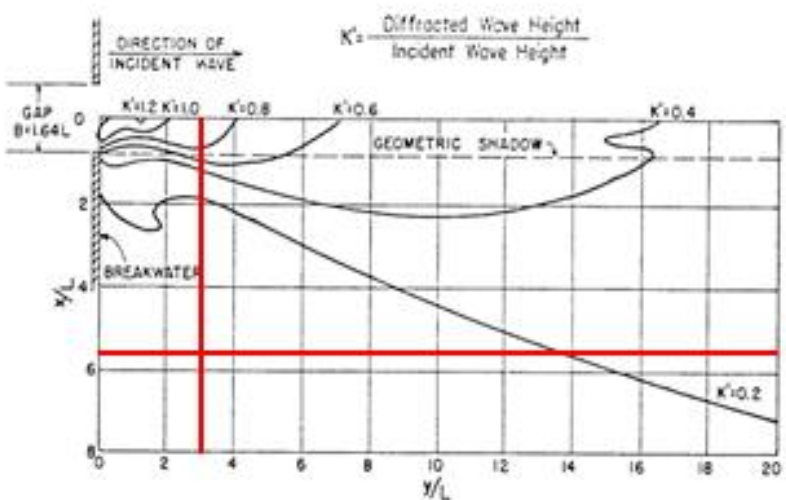

Gambar 9. Diagram Difraksi dengan $\mathrm{B} / \mathrm{L}=1.64$

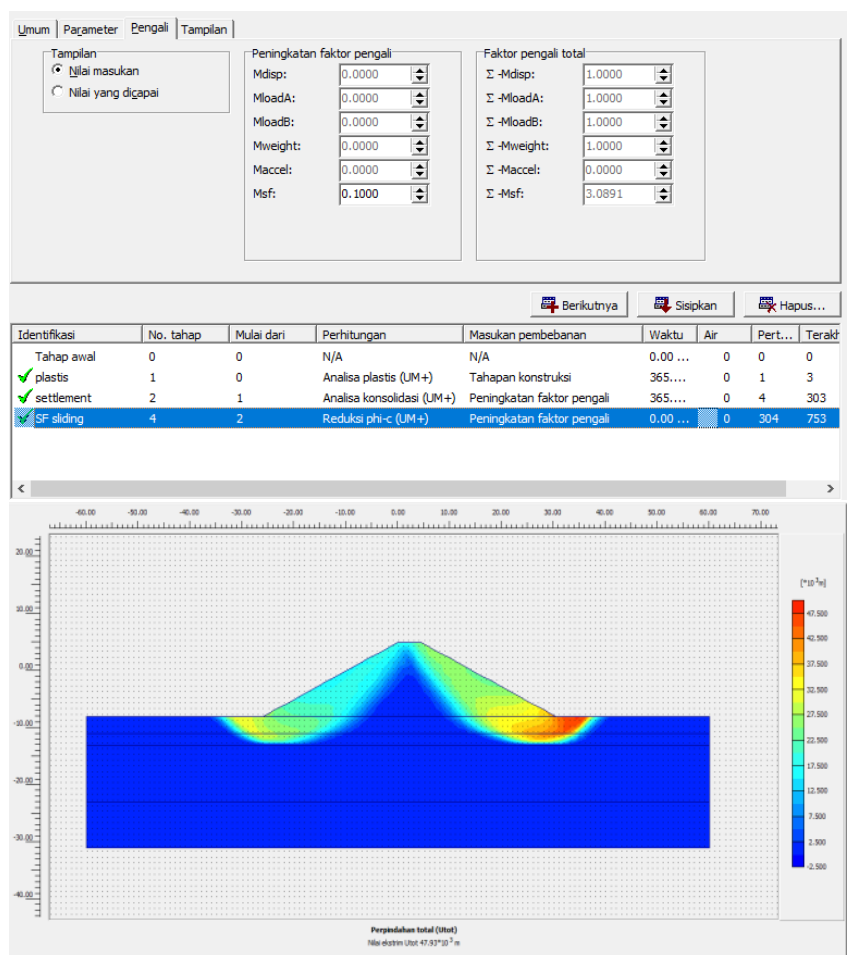

Gambar 10. Hasil Analisa Menggunakan Software Plaxis

dapat dilihat pada Gambar 9. Sehingga tinggi gelombang setelah difraksi pada titik titik yang ditinjau dapat dilihat pada Tabel 2.

Adapun desain untuk cross section breakwater yang terdiri dari berat armour unit setiap lapisannya, tebal lapisannya, dan lebar puncak dari breakwater.

Berat unit armour untuk setiap lapisan baik pada struktur kepala breakwater maupun pada struktur lengan breawater dapat dilihat pada Tabel 3.

Tebal setiap lapisan armour layer tersaji pada Tabel 4. Breakwater yang direncanakan akan mengalami penurunan pada tanah dasarnya (settlement) akibat beban breakwater yang besar. Besarnya settlement diasumsikan sebesar 1meter. Sehingga elevasi breakwater adalah sebagai berikut.

$$
\text { beda pasut } \quad=1.3 \mathrm{~m}
$$

Tabel 2.

Tinggi Gelombang Setelah Difraksi pada Titik Titik yang Ditinjau

\begin{tabular}{cccccccccc}
\hline \hline Titik & $\begin{array}{c}\mathrm{H}_{50} \\
(\mathrm{~m})\end{array}$ & $\begin{array}{c}\mathrm{T} \\
(\mathrm{s})\end{array}$ & $\begin{array}{c}\mathrm{L} \\
(\mathrm{m})\end{array}$ & $\begin{array}{c}\mathrm{x} \\
(\mathrm{m})\end{array}$ & $\begin{array}{c}\mathrm{y} \\
(\mathrm{m})\end{array}$ & $\mathrm{x} / \mathrm{L}$ & $\mathrm{y} / \mathrm{L}$ & $\mathrm{K}$ & $\begin{array}{c}\mathrm{H} \\
(\mathrm{m})\end{array}$ \\
\hline 1 & 3.7 & 10 & 89 & 492 & 286 & 5.5 & 3.2 & 0.1 & 0.4 \\
2 & 3.7 & 4 & 89 & 353 & 374 & 4.0 & 4.2 & 0.2 & 0.7 \\
3 & 3.7 & 4 & 89 & 201 & 446 & 2.3 & 5.0 & 0.1 & 0.4 \\
\hline \hline
\end{tabular}

Tabel 3.

Berat Unit Armour Setiap Lapisan

\begin{tabular}{cccc}
\hline \hline \multirow{2}{*}{ Lapisan Breakwater } & \multicolumn{2}{c}{ Berat (ton) } \\
& & Head Structure & Trunk Structure \\
\hline Primary Layer & $\mathrm{W}$ & 7.66 & 5.36 \\
Secondary Layer & $\mathrm{W} / 10$ & 0.77 & 0.54 \\
& $\mathrm{~W} / 200$ & 0.038 & 0.027 \\
Core Layer & $\mathrm{W} / 4000$ & 0.002 & 0.001 \\
& $\mathrm{~W} / 10$ & 0.77 & 0.54 \\
\hline \hline
\end{tabular}

Tabel 4.

Tebal Setiap Lapisan Armour Layer

\begin{tabular}{lcc}
\hline \hline \multirow{2}{*}{ Lapisan Breakwater } & \multicolumn{2}{c}{ tebal $(\mathrm{m})$} \\
& Head Structure & Trunk Structure \\
\hline Primary Layer & 2.9 & 2.6 \\
Secondary Layer & 1.4 & 1.2 \\
Berm & 1.4 & 1.2 \\
\hline \hline
\end{tabular}

$$
\begin{gathered}
\text { transmisi gelombang }=2.0 \mathrm{~m} \\
\text { settlement }=1.0 \mathrm{~m} \\
\text { elevasi puncak }=1.3 \mathrm{~m}+2.0 \mathrm{~m}+1.0 \mathrm{~m} \\
=4.3 \mathrm{~m} \approx 4.5 \mathrm{~m}
\end{gathered}
$$

Cek stabilitas pada breakwater diantaranya adalah cek terhadap settlement, puncture failure, dan sliding rotasional. settlement total yang terjadi untuk tinggi timbunan breakwater adalah sebagai berikut.

$$
\begin{gathered}
S=S_{c}+S_{i} \\
=0.48 \mathrm{~m}+0.03 \\
=0.51 \mathrm{~m}
\end{gathered}
$$

Cek stabbilitas terhadap puncture failure, SF dari timbunan breakwater adalah sebagai berikut.

$$
\begin{gathered}
S F=\frac{q_{\max }}{q} \\
=\frac{68.75 \mathrm{t} / \mathrm{m}^{2}}{24.3 \mathrm{t} / \mathrm{m}^{2}} \\
=2.83 \text { (aman) }
\end{gathered}
$$

Dengan kemiringan slope breakwater adalah 1:1.5 didapatkan nilai $\mathrm{SF}$ adalah 3.09 (SF> $\left.\mathrm{SF}_{\min }\right)$. Maka struktur breakwater tersebut aman terhadap sliding. Hasil yang didapatkan dapat dilihat pada Gambar 10.

\section{Rencana Anggaran Biaya}

Rencana anggaran biaya yang diperlukan untuk Biaya total yang dibutuhkan untuk membangun reklamasi dan breakwater ini adalah sebesar Rp. 578,489,189,000.00.

\section{DAFTAR PUSTAKA}

[1] M. Das, Mekanika Tanah (Prinsip-prinsip Rekayasa Geoteknis). Jakarta: Erlangga, 1995. 